\title{
Evolution retraces its steps to advance
}

\section{Bacteria in a long-term evolution experiment evolved a new metabolic trait via two separate mutations with opposite effects.}

\section{DANIEL J KLIEBENSTEIN}

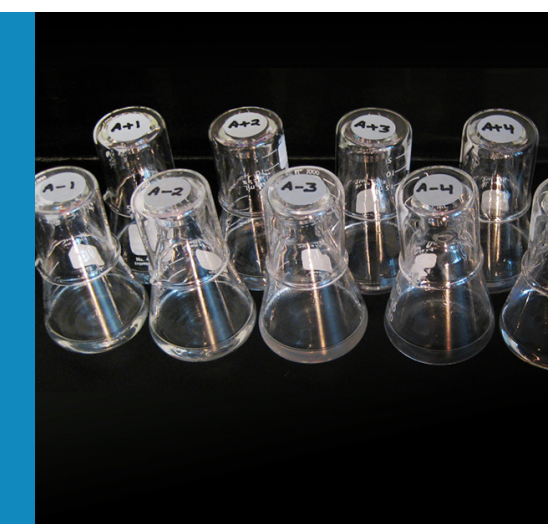

Related research article Quandt EM, Gollihar J, Blount ZD, Ellington AD, Georgiou G, Barrick JE. 2015. Fine-tuning citrate synthase flux potentiates and refines metabolic innovation in the Lenski evolution experiment. eLife 4:e09696. doi:

\subsection{4/eLife.09696}

Image Evolving populations of E. coli have been tracked for almost 30 years (Image credit: Brian Baer and Neerja Hajela)

(c) Copyright Kliebenstein. This article is distributed under the terms of the Creative Commons Attribution License, which permits unrestricted use and redistribution provided that the original author and source are credited.
0 election can increase the fitness of a species in a stable environment by acting on random mutations. The same process can also create new traits if there is a change in the environment. Metabolism may evolve largely via the creation of new traits that either allow the organism to make use of new energy sources or provide new defense mechanisms in a complex environment (Blount et al. 2012; Prasad et al. 2012). However, we do not fully understand how new metabolic traits evolve or how they are integrated into existing metabolic networks.

Studying the creation of new traits is greatly complicated because evolution usually occurs over relatively long timescales. However, the Lenski long-term evolution experiment was designed to alleviate this problem and has been running at Michigan State University since 1988 (Fox and Lenski, 2015). Now, in eLife, Jeffrey Barrick and colleagues - including Erik Quandt as first author - make use of this resource to describe the molecular evolution of a new metabolic trait in E. coli (Quandt et al. 2015).

The long-term evolution experiment started with twelve identical populations of $E$. coli. These bacteria were forced to grow on culture medium that contained an excess of citrate, but very little glucose. Thus, for tens of thousands of generations of $E$. coli, the bacteria have been selected to evolve to use citrate as their main carbon source. This is something that $E$. coli would not normally do if they had access to oxygen. However, one of the populations did indeed evolve this exact ability (Blount et al. $2008 ;$ 2012). Sequencing the genome of this unique population throughout the long-term experiment identified the molecular changes that had generated this new trait. The new trait required two separate mutations within the gene that encodes an enzyme called citrate synthase (Quandt et al. 2015).

Barrick and colleagues - who are based at the University of Texas at Austin and Michigan State - now show that these two mutations have opposing effects (Quandt et al. 2015). The first mutation, called gltA1, abolished feedback inhibition in the enzyme and allowed the bacteria to use citrate, albeit weakly. This initial mutation was then followed by evolutionary shifts in genes that transcriptionally regulate primary metabolism (Leiby and Marx, 2014). Critically, this new transcriptional environment made the initial gltA1 mutation detrimental to fitness which, in turn, led to the rapid selection of variants of the citrate synthase gene that made the enzyme less active. Thus, while two opposing mutations within a single gene were required, they had to 
occur in a specific order and this order caused the mutations to be positive in both instances.

These new results show that the apparently unwavering march of evolution towards a new trait hides a meandering process underneath. In particular, they show that mutations that were at one time beneficial can consequently become a drag on fitness, and that mutations within existing genes can allow the creation of a new metabolic trait. This is in contrast to the standard view that the creation of new genes, often by gene duplication, is essential to the evolution of new metabolic traits (Chae et al. 2014; Wisecaver et al. 2014).

The use of the long-term evolution experiment has illuminated the complex mechanisms that allow adaptation to a consistent selective pressure in a single direction. However, it is possible that fluctuating and unpredictable stresses in the environment are more important drivers of evolution in nature (Kerwin et al. 2015), so there is a need for long-term experiments that include such stresses. The work of Quandt et al. represents, I hope, only the beginning of our ability to empirically study evolution in action.

Daniel J Kliebenstein is an eLife Reviewing editor and is in the and is in the Department of Plant Sciences, University of California,Davis, Davis, United States kliebenstein@ucdavis.edu

Published 15 December 2015Competing interestsThe author declares that no competing interests exist.References

Blount ZD, Barrick JE, Davidson CJ, Lenski RE. 2012.

Genomic analysis of a key innovation in an experimental escherichia coli population. Nature 489 513-518. doi: 10.1038/nature11514

Blount ZD, Borland CZ, Lenski RE. 2008. Historical contingency and the evolution of a key innovation in an experimental population of escherichia coli. Proceedings of the National Academy of Sciences 105: 7899-7906. doi: 10.1073/pnas.0803151105

Chae L, Kim T, Nilo-Poyanco R, Rhee SY. 2014.

Genomic signatures of specialized metabolism in plants. Science 344:510-513. doi: 10.1126/science. 1252076

Fox JW, Lenski RE. 2015. From here to eternity-the theory and practice of a really long experiment. PLOS Biology 13:e1002185. doi: 10.1371/journal.pbio. 1002185

Kerwin R, Feusier J, Corwin J, Rubin M, Lin C, Muok A, Larson B, Li B, Joseph B, Francisco M, Copeland D, Weinig C, Kliebenstein DJ. 2015. Natural genetic variation in arabidopsis thaliana defense metabolism genes modulates field fitness. eLife 4:e05604. doi: 10 7554/eLife.05604

Leiby N, Marx CJ, Moran NA. 2014. Metabolic erosion primarily through mutation accumulation, and not tradeoffs, drives limited evolution of substrate specificity in escherichia coli. PLOS Biology 12: e1001789. doi: 10.1371/journal.pbio.1001789

Prasad KVSK, Song B-H, Olson-Manning C, Anderson JT, Lee C-R, Schranz ME, Windsor AJ, Clauss MJ, Manzaneda AJ, Naqvi I, Reichelt M, Gershenzon J, Rupasinghe SG, Schuler MA, Mitchell-Olds T. 2012. A gain-of-function polymorphism controlling complex traits and fitness in nature. Science 337:1081-1084.

doi: 10.1126/science.1221636

Quandt EM, Gollihar J, Blount ZD, Ellington AD, Georgiou G, Barrick JE. 2015. Fine-tuning citrate synthase flux potentiates and refines metabolic innovation in the lenski evolution experiment. eLife 4 e09696. doi: 10.7554/eLife.09696

Wisecaver JH, Slot JC, Rokas A, Stajich JE. 2014. The evolution of fungal metabolic pathways. PLOS Genetics 10:e1004816. doi: 10.1371/journal.pgen 1004816 